children in later years evince any special tendency to become insane $I$ am unable to say and it is doubtful whether a sufficient number of children could be followed far enough in life to enable this question to be satisfactorily answered. It is, however, abundantly clear that up to the age at which it has been possible to trace them they in no way differ from ordinary children. This fact is of considerable interest in connexion with "maternal impressions," for it would be difficult to conceive of a more profound mental change than is frequently present in the insanity of pregnancy, ranging as it does from the most violent and acute mania to a melancholia almost approaching stupor and yet, as has been seen, the child may be perfectly normal.

Many authorities hold the view that the mind of the mother is capable of exerting an influence upon the developing embryo, but I cannot but think that the facts here given are strongly opposed to any such view, and, as far as my own personal experience goes, all that $I$ can say is that in the investigation of nearly 200 cases of idiocy and imbecility I was unable to find evidence in a single instance of the operation of any such influence, although it must be admitted that such was frequently alleged.

On the other hand, it is plainly evident that when a strong morbid heredity exists the vitality of the child is so much impaired that its chances of surviving more than a few months are small, and I am convinced that this morbid hereditary influence plays a yery important part in the degeneration of the offspring and finally culminates in either idiocy or extermination.

Incidentally it may be noted that abnormalities of parturition do not occur with any greater frequency in these cases than in the outside population. Three children were stillborn and one was born prematurely, but the remaining 34 births were normal in every way and of the whole 38 only seven were illegitimate.

In view of the preceding facts I do not see what other conclusions can be drawn than that (1) the mental and physical condition of the child is in no wise influenced by the mere fact of the mother being insane during pregnancy; (z) neither is the condition of the child influenced by the variety of insanity, the duration of the attack, or the age of the mother, nor even directly by the number of attacks from. which the mother may have suffered; but that (3) this condition is directly dependent upon the presence or absence of morbid hereditary influences.

Guildford, Surrey.

\section{LIQUID AIR AS A FREEZING MEDIUM IN THE LABORATORY.}

BY W. H. B. STODDART, M.D., M.R.C.P. LOND. ASSISTANT MEDICAL OFFICER, BETHLEM AND BRTDEWEIT ROYAL HOSPITALS.

For the past month or so I have been using liquid air instead of ether as a freezing medium in the laboratory at the Bethlem Royal Hospital and I have found the advantages to be so great and the results so satisfactory that I have no hesitation in commending its general use to other pathologists.

Liquid air is obtained by mechanical compression of ordinary atmospheric air to one eight-hundredth of its volume and by removal of the impurities by fractional solidification. It is a fluid like water in appearance but of lower specific gravity. It boils at a temperature of $-312^{\circ} \mathrm{F}$. and therefore at the temperature of the atmosphere when placed in ordinary vessels. It evaporates, however, quite slowly when stored in the vacuum flasks used by the manufacturers. An untouched gallon evaporates from the storage flask in about six weeks. In ordinary constant use in the laboratory a gallon lasts a little longer than a fortnight Liquid air is therefore very much cheaper than ether for laboratory purposes. Further, it acts much more rapidly than ether-about from 20 to 30 compressions of the indiarubber bulb are always sufficient to freeze the gum and the tissue remains frozen much longer. On the other hand, tissues are not destroyed by liquid air-freezing more than by etherfreezing. Lastly, the unpleasant smell of ether is done away with and instead thereof a supply of pure air issues from the microtome. I have had an opportunity of inspecting the impurities removed from the atmosphere in the process of manufacture of liquid air and have observed that the stench from these is worse than that from the worst London fog. I regard this supply of pure air as most important; it makes pathological work much more pleasant and healthy. When working with liquid air the best method of ventilation for the laboratory is to shut all the windows and ventilators and to be satisfied with the pure air issuing from the microtome. It is no exaggeration to say that after a morning's work in the laboratory with liquid air I have felt as if I had been for a blow in the country.

The vacuum flasks in which the liquid air is stored are made of glass and each consists practically of two flasks one

FIG, 1.

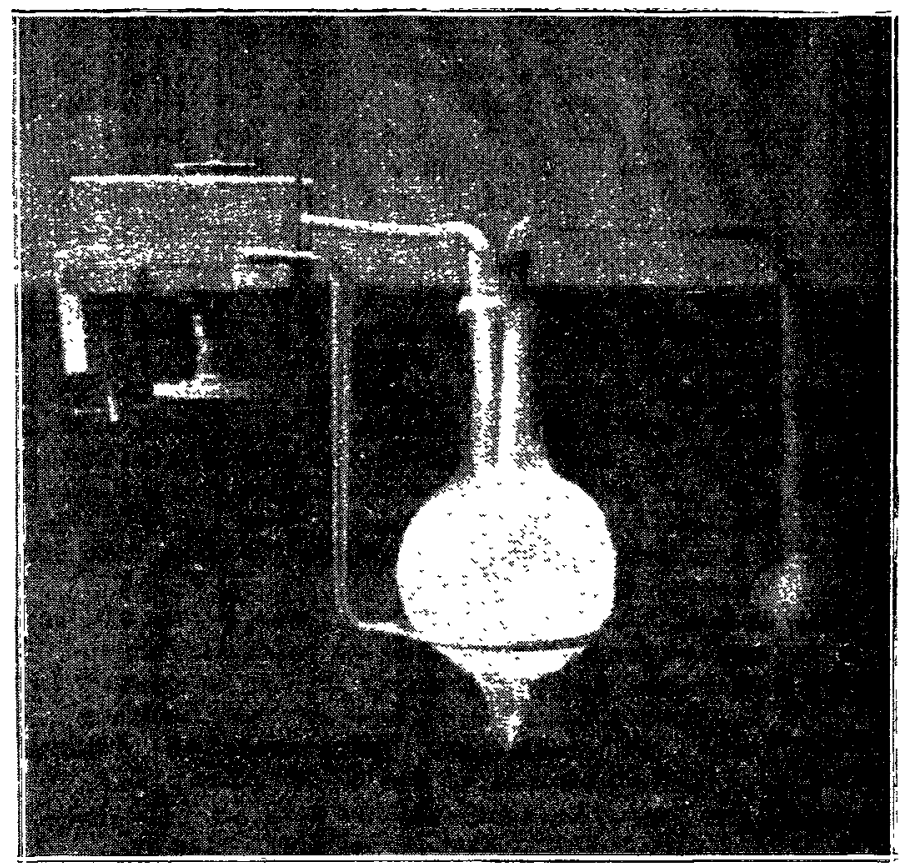

A Catheart microtome is shown on the left. The hrass attachment supporting the vacum flask is seen in the centre of ment supporting the racum flask is seen in the centre of (From a photograph.)

inside the other with a vacuum between the two. For use with a Cathcart microtome a support for one of the flasks is a necessary attachment. This attachment is shown in Fig. 1 .

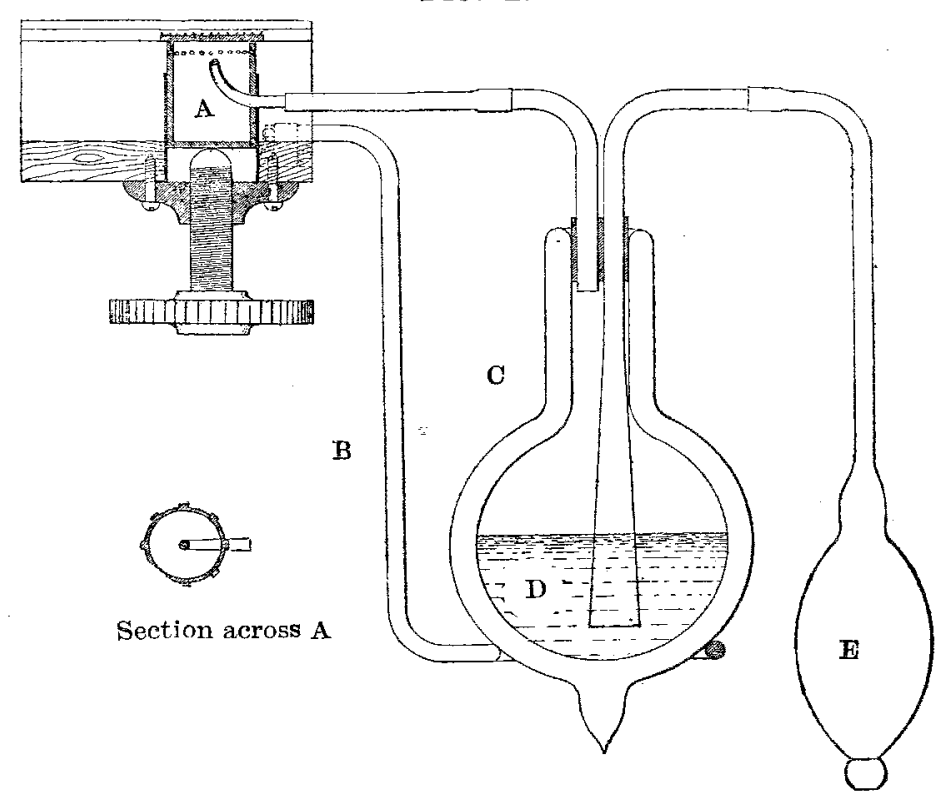

Sectional view. A is placed in the sliding cylinder of the microtome. The nozzle is shown on the right of this. $B$ brass support for, $\mathrm{C}$, vacuum flask containing, $\mathrm{D}$, liquid air $\mathrm{E}$, rubber bulb.

The inner sliding cylinder of the microtome also requires some modification. It should be of smaller diameter than is usual in the Cathcart microtome and should be fitted with vertical strips of brass This device is necessary for purposes 
of partial insulation and also to diminish the risk of the cylinders freezing together. A transverse section of the inner cylincler is shown in the small figure to the left of Fig. 2

A simple nozzle is fitted into the side of the cylinder and is turned up so as to play on the under surface of the plate. An indiarubber cork with two holes is fitted into the vacuum flask. Through one of these holes (the left in Fig. 2) is a glass tube passing from the vapour above the liquid to a piece of indiarubber tubing attached to the nozzle of the microtome. This indiarubber tubing freezes hard when the microtome is in use and tinus forms a further support for the flask. Through the other hole in the cork passes another piece of glass tubing one end of which dips below the surface of the liquid air while the other is attached to the valvular indiarubber bulb. It is necessary for this piece of glass tubing to be expanded at the lower end which dips into the liquid air. The whole apparatus is worked on the same princ1ple as a Junker's chloroform inhaler. By means of the valvular indiarubber bulb ordinary air is blown through the liquid air. The liquid air is vaporised and plays on the uniler surface of the plate of the microtome. As the atmospheric air passes into the liquid air the moisture condenses from the former on the inner surface of the glass tube which soon becomes biucked with ice unless it be dilated as recom. mended above and as shown in Fig. 2 .

The above apparatus may be seen at work at Mr. Charles Baker's, 244, High Holborn, London, W.C., and is sold by him for 30s. The present form of Cathcart's microtome as modified for use with liquid air is sold for 15s. Liquid air is to be obtained for $2 d$. per gallon from the Liquid Air Power and Automobile Co., Limited, 29A, Gillingham-street, Pimlico, London, S.W.

In conclusion, I ought to say that I can personally lay no claim to any originality in connexion with the above. The idea of using liquid air for freezing in the laboratory is due to Dr. T. B. Hyslop, superintendent of the Bethlem Royal Hospital, and the mechanical adaptation of Cathcart's microtome for the purpose is due to Mr. Hans Knudsen of the Liquid Air Power and Automobile Co., Limited, to whom I now tender my warmest thanks for his kindly interest and gener us assistance.

Bethlem Royal Hospital, S.E.

\section{SOME OF THE SURGICAL ASPECTS OF GLYCOSURIA AND DIABETES.}

BY LLEWELLYN C. P. PHILLIPS, F.R C.S. ENG.,

RESIDENT SURGICAL OFFICER, KASR-EL-AINI HOSPITAL, CAIRO, EGYPT LATE DEMONSTRATOR OF ANATOMT, ST. BARTHOLOMEW'S HOSPITAL. (Concluded from $p .1316$.

CLASS III. (continued).

Operations on the Rectum.

ExcIsIon of the rectum by Kraske's operation has been performed on a man, aged 60 years, for carcinoma; he was very corpulent and his liver was enlarged. At the time of operation there was no sugar in his urine, though there was a history that he had suffered from diabetes and albuminuria five years before and had been under treatment at Karlsbad with the result that the sugar was absent for the two years immediately preceding the operation; there was, however, still a trace of albumin. There was a history of rectal trouble for two years with the passage of blood for one year. After 'xcision the wound was plugged with iodoform dressings. The same evening his urine contained 2.4 per cent. of sugar. The next day he was restless and iodoform poisoning being suspected the dressings were changed, the sugar disappearing meanwhile. Three days later it reappeared and iodine was no longer detected in the urine. The next day there was a trace of iodine and 4 per cent of sugar. Four days later he died comatose. The coma may have been uræur ic in origin, as opium had been administered every two hour and his kidneys were unsound. Desprès records the removal of hremorrhoids with the écraseur, the patient recuvering. The percentage of sugar was from 0.8 to 1.5 .

In connexion with these cases must be considered a case recorcled by Wallace, of a man, aged 72 years, who underwent excision of the rectum for carcinoma. The wound became very foul after a few days. Simultaneously sugar appeared in his urine and reached 2376 grains in 24 hours This fell to a trace in a month. The highest temperature recorded was $101^{\circ} \mathrm{F}$. Wallace considered this to be temporary glycosuria. The patient was lost sight of afterwards. (Vide Table VII.)

\section{Operations on the Extremities.}

A large popliteal aneurysm was excised by Trendelenburg. The patient was a man, aged 64 years. Ether was administered and the operation was done with the aid of Esmarch's bandage ; it lasted 60 minutes and there was much bleeding on removal of the bandage. He had much pain on recovery from the anæsthetic. 'The next day his condition was good. On the third day, however, his temperature rose to $103.2^{\circ} \mathrm{F}$. and there was slight ptosis on the right side. Later on the same day he became unconscious. A search for sugar was now made for the first time; 6.7 per cent. was found; a slight fruity odour was observable. That evening his temperature rose to $1043^{\circ}$; the next morning he died comatose. Post mortem a dilated heart, emphysema, and atheromatous arteries were found.

At St. Bartholomew's Hospital the superficial femoral artery was ligatured for a left popliteal aneurysm by Mr. Howard Marsh. The patient was 34 years of age and he had contracted syphilis seven years previous]y. Sugar was found in his urine tor the first time on the day of operation (? before or after the operation). 13 days later sugar was still present. He was discharged a month later surgically well; no mention of diet is made. 14 months later he was admitted under the care of Sir Lauder Brunton with wellmarked diabetes (the urine was of specific gravity 1040, the amount was six pints, and it contained $\mathbf{1 3 . 8}$ per cent. of sugar ; the total amount present per diem before death was 7262 grains). He died comatose. This was probably a case of diabetes throughout, though Fort's case must be remembered of diabetes the result of an anæsthetic. (St. Bartholomew's Hospital Male Surgical Register, 1896, vol. iv., No. 1696.)

In $1900 \mathrm{Mr}$. H. T. Butlin amputated the right hand of an engine-driver for epithelioma. He was 45 years of age and was a big corpulent man. On admission his hand was swollen on the inner side and the skin was red, smooth, and painful. His temperature was $97.6^{\circ} \mathrm{F}$. and his urine was of specific gravity 1028 and contained 5 per cent. of sugar. The swelling was explored under an anæsthetic and a sinus was found; a piece was removed for microscopical examination. This proving to be epithelioma an amputation was performed through the wrist. Gas and ether were administered on each occasion. All carbohydrates were withheld from his diet. He was quite free from pain the next few days but his temperature gradually rising to $100^{\circ}$ on the fourth day the wound was dressed and sloughing of the flaps was discovered The sloughs separated gradually and on his discharge the wound had practically healed. The following table shows the state of the urine :-

\begin{tabular}{c|c|c|c|c|c}
\hline Date. & $\overbrace{\text { in }}^{\text {Amount }}$ & $\begin{array}{c}\text { in cubic } \\
\text { centi- } \\
\text { ounces. }\end{array}$ & $\begin{array}{c}\text { Specific } \\
\text { gravity. }\end{array}$ & $\begin{array}{c}\text { Per- } \\
\text { centage } \\
\text { of } \\
\text { sugar. }\end{array}$ & $\overbrace{\text { Grains. }}^{\text {Total amount of }}$ \\
sugar.
\end{tabular}

On July 4th, 5th, and 9th only traces of sugar were discovered. The ferric chloride reaction was never present. The percentage of sugar in this case was high and did not materially diminish until the sixteenth day in spite of diat; it eventually became a mere trace. The euphoria during the period of sloughing is noteworthy. He was readmitted in 